\title{
MEDIAÇÃO DE CONFLITOS NAS ESCOLAS E A ATUAÇÃO DO PROFESSOR MEDIADOR ESCOLAR E COMUNITÁRIO.
}

\author{
Eva Cristina Aurélio Menezes ${ }^{1}$, Lúcia Maria Gomes Corrêa Ferri ${ }^{2}$ \\ ${ }^{1}$ UNIP. ${ }^{2}$ Docente do Mestrado em Educação - UNOESTE. E-mail: evacrismenezes@gmail.com
}

\section{RESUMO}

Nas escolas ocorrem diversos conflitos, com vistas a diminuí-los, a Secretaria da Educação do Estado de São Paulo, na resolução SE 19/2010, deliberou a função de Professor Mediador Escolar e Comunitário. Este estudo teve como objetivo investigar como o Professor Mediador Escolar e Comunitário da Diretoria de Ensino-Região de Assis-SP, está vivenciando as situações de conflito no ambiente escolar. A metodologia utilizada foi a qualitativa com entrevista semi-estruturada com professores mediadores e alunos e para análise das entrevistas a técnica do Discurso do Sujeito Coletivo. Verificou-se que os mediadores recebem apoio da supervisão do Sistema de Proteção Escolar, e nem todos o recebe da gestão escolar. Estes educadores reclamam da falta de apoio dos pais e os tipos de conflitos mais comuns que enfrentam são: os de convivência, os relacionados à sexualidade aflorada no Ensino Fundamental II e o uso de drogas no Ensino Médio. Para os alunos, o PMEC contribui para resolver os conflitos na escola, pois ouve, orienta, evita agressões e refaz as amizades. Desta forma, constatou-se que estes profissionais estão em constante construção de sua identidade. A pesquisa subsidia a discussão sobre tal função e contribui para a reflexão de como as políticas públicas educacionais estão sendo implementadas.

Palavras-chave: Conflito. Professor Mediador Escolar e Comunitário. Gestão.

\section{1-INTRODUÇÃO}

A violência sempre esteve presente na sociedade humana. E, apesar dos avanços tecnológicos da sociedade atual, a violência ainda permeia nosso cotidiano. A escola como parte da sociedade não é uma ilha e atos violentos também estão dentro do ambiente escolar e isto não é um fenômeno novo. Seja por um aluno levar uma arma para mostrar "o curioso artefato" para os colegas, pelos casos de "bulling", pelas agressões físicas, pelos danos ao patrimônio ou ainda, pelo tráfico e consumo de drogas; se edificando em comportamentos sem nenhuma causa aparente que os justifique. Precipuamente, não podemos nos esquecer de chacinas frequentes em escolas americanas e europeias, refletidas em verossimilhança em nosso país, como em Realengo - RJ, onde 12 crianças morreram.

O mais recente esforço para conter os conflitos e a violência escolar, fruto da justiça restaurativa, foi promovida pelo Governo do Estado de São Paulo (Secretaria da Educação) por meio da Resolução SE № 19/2010, criando o Sistema de Proteção Escolar e a função de Professor Mediador Escolar e Comunitário (PMEC), tema desta investigação. 
Esta pesquisa partiu do seguinte questionamento:

De que maneira o professor mediador escolar e comunitário está enfrentando as situações de conflito do ambiente escolar?

O estudo possui relevância social e política, pois aborda uma recente política educacional do Estado de São Paulo e que até o presente tem recebido pouca atenção dos teóricos. Deste modo, podemos esperar melhor compreensão do problema da violência nas escolas, através da percepção de alunos e professores sobre a função de Professor Mediador Escolar e Comunitário. Para a área da gestão educacional o tema proposto é de fundamental importância, uma vez que quanto mais reflexões e evidências forem encontradas sobre o tema, maior será a contribuição para a melhoria da educação no país, especialmente no Estado de São Paulo, bem como para uma significativa melhoria da ação do gestor no ambiente escolar.

E teve por objetivos: a) Diagnosticar como o Professor Mediador Escolar e Comunitário (PMEC) contribui para a gestão das escolas da Diretoria de Ensino-Região de Assis; B) Caracterizar seu perfil; c) Identificar o tipo de conflito que tem mais dificuldade em administrar; d) Levantar a percepção dos alunos sobre o papel do PMEC, relacionando seu gênero, idade e série às situações de conflitos que vivenciam.

Para alcançarmos os objetivos propostos utilizamos a abordagem qualitativa, com estudo de caso através de entrevista semiestruturada com quatro Professores Mediadores Escolares e Comunitários e com oito alunos das escolas pesquisadas. E, como ferramenta de análise das entrevistas usamos a técnica do Discurso do Sujeito Coletivo.

\section{2-REFERENCIAL TEÓRICO}

\section{1-A Mediação e sua origem}

Originária da Grécia Antiga, passando pelo Código de Hamurabi e pelo Antigo Testamento, a mediação não é uma ideia contemporânea. Foi introduzida no Brasil na década de 1980 (FERRARI; SACHET; SILVA, 2012). Surgiu como uma forma de luta contra a insatisfação com o sistema judicial, uma forma de justiça informal, ou seja, como um modo alternativo de resolução de litigiosidade para além da justiça formal (BONAFÉ-SCHMITT, 2007). Para More, quando o homem passou a viver em bandos, os conflitos já existiam e não havia mediação.

Hoje, a mediação é considerada como uma forma de intervir numa situação difícil entre duas pessoas (físicas ou morais), consiste no fato de transmitir a palavra de uma pessoa que se encontra bloqueada por uma ou várias razões - administrativa, logística ou emocional. 
Tratando-se de mensagem a transmitir, reveste uma dimensão pedagógica. Implica qualidades de "porta-voz" por parte do mediador (LASCOUX, 2006).

Segundo RUOTTI e ALVES e CUBAS (2009), a mediação tem auxiliado na diminuição de violência em vizinhanças e em escolas. Algumas escolas tem recrutado e treinado estudantes para serem mediadores. Os mediadores auxiliam as pessoas em conflito a acalmar a raiva e chegar em um entendimento pacífico.

Como vimos, a ideia de usar o processo de mediação nas escolas veio de experiências realizadas em diversos países, por meio judicial, que trazida para o ambiente escolar pode auxiliar na diminuição das situações de violências nas escolas.

\section{2- O Professor Mediador Escolar e Comunitário (PMEC)}

Com vistas à diminuição da violência nas escolas públicas do Estado, em 13 de fevereiro de 2010, o então Secretário da Educação do Estado de São Paulo, Paulo Renato de Souza (1945-2011), delibera a Resolução SE (Secretaria da Educação) no 19/2010, instituindo o Sistema de Proteção Escolar, criando a função de Professor Mediador Escolar e Comunitário.

O artigo 70 da Resolução SE 19/2010 revela as ações específicas do Sistema de Proteção Escolar, ressaltando as atribuições desse professor que são: I - adotar práticas de mediação de conflitos no ambiente escolar e apoiar o desenvolvimento de ações e programas de Justiça Restaurativa; II - orientar os pais ou responsáveis dos alunos sobre o papel da família no processo educativo; III - analisar os fatores de vulnerabilidade e de risco a que possa estar exposto o aluno; IV - orientar a família ou os responsáveis quanto à procura de serviços de proteção social; $\mathrm{V}$ - identificar e sugerir atividades pedagógicas complementares, a serem realizadas pelos alunos fora do período letivo; VI - orientar e apoiar os alunos na prática de seus estudos.

O projeto surgiu no Estado de São Paulo em fase de adequações, iniciando com 1.000 professores no ano de 2.010 e em 2.011 foram adicionados mais 1.000 escolas. Para o ano de 2.012 estão sendo previstos mais 1.000 professores com essa função. Esses professores estão sendo capacitados através de um curso à distância, oferecido pelo Sistema de Proteção Escolar/ Escola de Formação, e reuniões pedagógicas promovidas pela Diretoria de Ensino. Os 1.000 primeiros professores mediadores participaram do "1으 Encontro de Mediação Escolar e Comunitária", ocorrido em Serra Negra-SP, de 9 a 11 de junho de 2.010. 
No início do projeto em 2.010 esse profissional apresentava uma carga horária de 24h semanais. No ano de 2.011 (Resolução SE 18/2011) a carga horária foi ampliada para 30 horas semanais (Resolução SE 01/2011) e no ano de 2.012, para 40h semanais (Resolução SE 07/2012).

O projeto baseia-se nos princípios do Programa de Justiça Restaurativa, instaurado pela Resolução 2002/12, da ONU. A Justiça restaurativa é definida como um processo no qual a vítima e o ofensor, e participam ativamente na resolução das questões oriundas do crime, geralmente com a ajuda de um facilitador (ONU, 2012/12). E, ao invés de se preocupar em transgressões e culpados, se pauta sobre a possibilidade concreta de participação individual e social, democratização do atendimento, acesso a direitos, afirmação de igualdade em espaços de diálogo, valorização das diferenças, através de processos sócio- pedagógicos que levem em consideração os danos, os responsáveis pela infração e os prejudicados pela infração (AGUINSKY; CAPITÃO, 2008).

As práticas restaurativas estão sendo aplicadas aos sistemas de Justiça em vários países do mundo como forma de garantia de direitos humanos e fundamentais, como estratégias de enfrentamento da violência e para a não-violência na resolução de conflitos. No Brasil, a Justiça Restaurativa vem sendo aplicada desde 2003, pelo Instituto de Direito Comparado e Internacional de Brasília (IDCB) (COSTA et al, 2008).

\section{3-METODOLOGIA}

\section{1-Contextualização da pesquisa}

A Diretoria de Ensino-Região de Assis abrange 41 escolas em 14 municípios. No ano de 2012, destas escolas, apenas 14 possuíam o Professor Mediador Escolar e Comunitário, distribuídos em 4 municípios: 10 em Assis, 1 em Candido Mota, 2 em Paraguaçu Paulista e 1 em Palmital. Destes profissionais, apenas um é (1) pertencente ao sexo masculino.

A pesquisa foi realizada em quatro escolas estaduais da Diretoria de Ensino-Região de Assis/SP, pertencente à Secretaria de Estado da Educação-Subsecretaria de Articulação Regional. Com quatro professores mediadores escolares e comunitários: 3 da cidade de Assis e 1 da cidade de Cândido Mota. Tal escolha determinou a seleção aleatória de dois alunos, os quais foram atendidos pelo professor mediador escolar e comunitário. 


\section{2-Instrumentos e procedimentos de coleta}

A coleta de dados foi realizada nos meses de maio e junho de 2012, por meio de entrevista semiestruturada com quatro professores mediadores escolares e comunitários, e com oito alunos, dois de cada escola pesquisada.

$O$ roteiro das questões das entrevistas foi elaborado baseando-se na revisão de literatura, levando em consideração os objetivos da pesquisa.

Nas seis primeiras questões da entrevista ao PMEC procuramos traçar o perfil deste profissional e nas demais compreender a frequência com que recebe orientações de seu supervisor, quais e quantos conflitos que existem na escola, quais os tipos mais difíceis de serem administrados, por que escolheu a função e quais as dificuldades que encontra no exercício desta função.

Quanto à entrevista realizada com os alunos, nas quatro primeiras questões procuramos traçar um perfil do aluno e nas demais traçar o papel do PMEC segundo a visão dos alunos; para isso foram feitas questões relacionadas à importância de um mediador na escola, se o PMEC resolve os conflitos, se o aluno precisou do mediador e em quais situações.

A presente pesquisa baseou-se em estudo de caso, com a utilização da entrevista semiestruturada, cujos procedimentos metodológicos desta pesquisa, obedeceram a uma abordagem qualitativa.

Na determinação da amostra foi levado em consideração o fato de que na Diretoria de Ensino-região de Assis existem 14 PMECs, destes apenas um é do sexo masculino. Devido ao fato do mediador do sexo masculino pertencer à escola da pesquisadora, ele não fez parte da amostra. Os alunos foram escolhidos por sorteio dentre os que foram atendidos pelo professor mediador.

\section{4-RESULTADOS}

Foi feita uma leitura qualitativa, embasada na análise de conteúdo do material levantado em entrevistas semiestruturadas; destes depoimentos depreenderam-se o discurso do sujeito coletivo.

As entrevistas semiestruturadas foram trabalhadas nas seguintes operações, para atender a construção do discurso do sujeito coletivo. (LEFEVRE; LEFEVRE, 2005). Coleta das Expressões - Chave (E-Ch); levantamento das Idéias Centrais (ICs); Ancoragens (ACs); e formação do Discurso do sujeito coletivo (DSCs) propriamente dito. 


\section{1- Perfil das escolas pesquisadas}

Por meio da análise dos resultados obtidos no perfil das escolas pesquisadas, percebemos que duas são escolas de período integral no Ensino Fundamental, atendendo também o Ensino Médio. Duas delas atendem o Ensino Fundamental e Médio regular. Três escolas atendem nos três turnos e apenas uma não atende alunos no período noturno. As escolas possuem de 290 a 800 alunos. Apenas uma escola possui a modalidade de Educação de Jovens e Adultos (EJA).

\section{2- Perfil do Professor Mediador Escolar e Comunitário pesquisados.}

Por meio da análise dos resultados obtidos no perfil dos professores mediadores escolares e comunitários, foi possível observar que os pesquisados são todos pertencentes ao sexo feminino, dois apresentam formação em Pedagogia, Psicologia e Filosofia, um em Letras e um em Educação Física. A idade dos professores situa-se entre 29 e 53 anos. Apenas um professor não fez curso de especialização. 0 tempo de magistério situa-se de 8 a 20 anos. 0 tempo de atuação como professor mediador escolar e comunitário varia de 4 meses a 2 anos e meio.

\section{3-Perfil dos alunos entrevistados}

Por meio da análise dos resultados obtidos no perfil dos alunos pesquisados, verificamos que seis (6) pertencem ao sexo feminino e dois (2) ao sexo masculino, a idade variou de 11 a 17 anos. Quanto às séries dos alunos, percebemos que três estavam no oitavo ano, três no segundo ano do Ensino Médio, um aluno no sexto ano e um aluno no terceiro ano do Ensino Médio. As séries dos alunos situaram-se entre o 6으 ano e o 3o ano do Ensino Médio.

\section{4-Análise da Entrevista com o Professor Mediador Escolar e Comunitário.}

Dos professores mediadores entrevistados apenas um (1) queixa-se de não ter apoio da direção da escola. Um relata receber todos os conflitos da escola para mediar. Estes professores acreditam que as escolas são rodeadas por muitos conflitos e que muitos destes conflitos já vêm das famílias, citados por dois PMECs. Reclamam que falta apoio dos pais e da comunidade no entorno da escola.

Dos entrevistados três (3) relataram o conflito da sexualidade aflorada nas séries iniciais do Ensino Fundamental II, dois citaram os problemas acarretados pelo uso de drogas e 
dois, os conflitos causados por brigas entre alunos. Também foram citados os conflitos de alunos com liberdade assistida e os de alunos com baixa autoestima.

Dois (2) professores mediadores relataram a falta de apoio tanto dos pais, quanto da comunidade como um problema difícil de ser administrado. Dois relataram que o uso de drogas também é um fato muito complicado de se lidar e apenas um (1) cita o problema da sexualidade como difícil de ser administrado.

Três (3) professores mediadores citaram que escolheram essa função porque estavam com poucas aulas e possuíam a categoria requerida pelo decreto. Dois citaram que via na função um desafio. Dois relataram que se preocupavam com os alunos e queriam ajudá-los, já um professor relatou que escolheu a função pela oportunidade de aperfeiçoamento como psicóloga.

$E$, por fim, dois relataram que a maior dificuldade que enfrentaram é não terem um espaço próprio para atender os alunos. Um PMEC relatou a dificuldade de ganhar confiança dos alunos e dos pais, e também foram citados a falta de apoio da comunidade e o fato de serem usados para várias funções na escola.

\section{5-Análise das entrevistas com os alunos.}

Dos alunos entrevistados todos concordam que o PMEC resolve os conflitos na escola. Três relataram que ele ouve e orienta. Um citou que ele ajuda a refazer as amizades perdidas; outro que ele separa agressões.

Cinco relataram que precisaram do PMEC devido a brigas com colegas, dois citaram que foram encaminhados quando desrespeitaram as regras da escola. Os casos de fofoca, dor, queixas contra colegas e nas situações que não sabiam como agir foram citados apena uma vez.

Todos concordaram que é importante ter um PMEC na escola. Dois deles ressaltaram que o PMEC promove a paz, dois que resolve o problema mais rápido. Também foram citados: que ele entende os alunos, forma pessoas de caráter, ajuda a descobrir a verdade, aconselha e melhora a escola.

Quatro concordaram que o PMEC é mais eficiente para resolver os problemas, dois ressaltaram que todos na escola são importantes na resolução de conflitos. Os inspetores e os coordenadores foram citados apenas uma vez. 


\section{5-CONSIDERAÇÕES FINAIS}

Em relação ao PMEC o que nos chama mais a atenção é a intensa busca pela identidade profissional. Eles estão incertos quanto à sua função no ambiente escolar, e muitos acabam realizando outras funções, algumas até distantes de suas atribuições. Outros nem tem um local adequado para "mediar os conflitos". Por tentativa e erro, vão se construindo, se refazendo, aprendendo uns com os outros, estudando sozinhos, buscando apoio da comunidade, mas ainda não estão seguros quanto ao seu real papel na escola muitos chegam a se sentir "inspetores de luxo", outros como gestores, mas na verdade são professores com as mais variadas habilitações, que não tem um cargo efetivo e que no momento estão na função de PMEC e cientes de que a qualquer momento poderão mudar, pois como a atribuição é por perfil, o diretor da escola pode trocá-lo. Infelizmente, são figuras transitórias, que estão atuando sem nenhuma estabilidade, além daquela que a lei e sua categoria oferece por enquanto.

Percebemos também que alguns PMECs acreditam que uso de drogas é problema da polícia, e que não há como interferir, crença equivocada, pois é na escola que há a vantagem de selecionar usuários que estão em fases mais iniciais do problema e definir estratégias de prevenção. Porém o PMEC apresenta dificuldade em enfrentar esse problema na escola.

Os depoimentos apresentados pelos alunos evidenciam que o PMEC resolve os conflitos na escola, pois ouve, orienta, separa agressões e refaz as amizades. Esse fato se deve à disponibilidade do profissional para as práticas de mediação de conflitos é um profissional que está na escola com essa finalidade. $\mathrm{O}$ diretor nem sempre possui disponibilidade para escutar e conversar com o aluno, chamar as partes envolvidas num conflito e mediar todo o processo, devido às inúmeras tarefas requeridas pela gestão escolar.

Com relação aos alunos, a categoria que se sobressai é a questão cultural, que na escola toma grandes proporções. Muitos alunos que são atendidos pelo PMEC apresentam problemas relevantes, que poderiam ter sido resolvidos na sala de aula pelo próprio professor da classe, e que tendo o PMEC na escola, é como se houvesse uma obrigação de "dar trabalho a ele". Os alunos provêm das mais variados camadas sociais e o modo como são educados se refletem na escola, e os que nela trabalham, sozinhos não são capazes de mudar uma sociedade e uma cultura de indisciplina e violência. Os alunos sentem-se mais apoiados com a presença do PMEC na escola, sentem que há alguém a disposição para ouvi-lo e compreende-lo, embora muitas vezes não queiram aceitar os seus conselhos. 
Percebemos que dos alunos entrevistados, a maioria pertence ao sexo feminino, o que nos leva a questionar se a maioria dos atendimentos do mediador são de alunos deste sexo, ou se são elas que procuram mais a orientação do mediador.

Outro problema apontado pela pesquisa está relacionado à alimentação dos alunos, pois um aluno relata que não conseguia comer na escola e por isso foi atendido pelo PMEC. Fato que comumentemente ocorre nas escolas de tempo integral, pois muitos alunos não se adaptam à alimentação fornecida e recusam-se a alimentarem-se.

O problema do PMEC foi o modo como a função foi implantada nas escolas, sem preparação prévia destes profissionais, em algumas escolas não há nem estrutura física necessária para este profissional atuar com mais eficácia.

As respostas obtidas dos alunos revelaram que é uma função importante nas escolas públicas, pois só veio a somar na gestão da escola. A escola está enfrentando os mais variados tipos de conflitos desde os mais simples aos mais complexos e essa investigação nos possibilitou compreender melhor, como PMECs e alunos estão enfrentando esses conflitos nas escolas. Pudemos perceber durante as entrevistas que estes profissionais estão dispostos a falar sobre a função, mesmo não tendo uma ideia muito clara dela e também a realizar um bom trabalho, falam com motivação, mesmo muitas vezes não tendo a formação necessária e nem os recursos disponíveis para tal. As respostas obtidas pelos PMECs revelaram que esses professores, mesmo enfrentando os conflitos sem o preparo adequado, estão se empenhando em atuar corretamente, que em alguns casos não conseguem lidar com todos os problemas indisciplinares da escola como o abuso de drogas e a sexualidade aflorada, apontados como os conflitos mais difíceis de mediar.

Percebemos que o PMEC necessita do apoio de todos da comunidade escolar, pois sozinho não é capaz de resolver os conflitos dos alunos e principalmente, se os pais não o ajudarem, o PMEC pouco pode fazer para que o conflito daquele momento não se repita. Quanto ao uso de drogas, o PMEC não se sente preparado para media-lo, pois muitos outros fatores sociais estão envolvidos.

A escolha da função pelos PMECs é oriunda dos mais diversos motivos, mas o que mais nos chama a atenção é que alguns escolheram a profissão exatamente por terem a categoria expressa na lei e como forma de melhora das condições de vida ao terem mais aulas, no início nem sabiam como seria a função. Alguns também relataram a necessidade de ajudar os alunos como um motivo para escolherem a função. 
Os casos de brigas na escola foram bastante comuns nas escolas pesquisadas os quais foram citados tanto pelos PMECs entrevistados quanto pelos alunos. Percebemos que os PMECs são chamados a orientar os mais variados tipos de conflitos que ocorrem no dia a dia escolar, desde alunos com algum tipo de dor, desrespeito às regras escolares, queixas de alunos contra outros alunos até situações em que necessitam de algum conselho.

Por fim, o presente estudo permitiu conhecer uma parcela dos problemas que o profissional tem enfrentado e o professor mediador escolar e comunitário deve escolher de acordo com suas experiências a melhor forma de mediação dos conflitos que ocorrem na escola, pois não teve uma formação para a mediação.

\section{REFERÊNCIAS}

AGUINSKI, B.;CAPITÃO, L. Violência e socioeducação: uma interpelação ética a partir de contribuições da Justiça Restaurativa. Rev. Katál. Florianópolis, v.11, n.2, p.257-264, jul./dez. 2008.

BONAFÉ-SCHMITT, J. P. Conferência de Jean-Pierre Bonafé Schmitt: Formação e Mediação Instituto de Educação e Psicologia da Universidade do Minho - 4/06/07, disponível em http://www.forum-mediacao.net/module2display.asp?id=47\&page=1, acessado em 09/01/2013.

CHRISPINO, A. Gestão do conflito escolar: da classificação dos conflitos aos modelos de mediação. Ensaio: aval. pol. públ. Educ. Rio de Janeiro, v.15, n.54, p. 11-28, jan./mar. 2007.

COSTA, M. M. M. ; PORTO, R. T. C. Justiça restaurativa e educação: o poder de atuação dos autores sociais para a consolidação da cidadania. Revista da Ajuris, v. 110, p. 289-302, 2008. ; Meio de divulgação: Impresso; ISSN/ISBN: 16791363.

FERRARI, G. M. R.; SACHET, E. M.; SILVA, A. C. A Mediação como Alternativa na Solução de Conflitos em Processos de Família. 07/04/2012. Disponível em http://www.tex.pro.br/tex/listagem-de-artigos/324-artigos-abr-2011/7979-a-mediacao-comoalternativa-na-solucao-de-conflitos-em-processos-de-familia, acessado em 07/01/2013.

LASCOUX, J. L. O que é a mediação? Mediatoroscope, 2006. Disponível em http://www.forummediacao.net/module2display.asp?id=39\&page=2, acessado em 01/09/2012.

LEFEVRE F.; LEFEVRE A.M.C. Depoimentos e discursos: uma proposta de análise em pesquisa social. Brasília: LiberLivro, 2005.

NAZARETH, E. R. Mediação: o conflito e a solução. São Paulo: Art Paubrasil, 2009.

ONU. Resolução 2002/12 - Princípios Básicos para utilização de Programas de Justiça Restaurativa em matéria criminal. Disponível em http://justicarestaurativaemdebate.blogspot.com/2008/07/resoluo-200212-do-conselhoeconmico-e.html, acesso em 22/11/2011. 
RUOTTI, C; ALVES, R; CUBAS, V. O. Violência na escola: um guia pra pais e professores. Imprensa Oficial do Estado de São Paulo. Andhep: Associação Nacional de Direitos Humanos Pesquisa e Pósgraduação, 2009.

SÃO PAULO. Secretaria da Educação. Resolução SE 19, de 13 de fevereiro de 2010.Institui o Sistema de Proteção Escolar na rede estadual de ensino de São Paulo e dá providências correlatas. Disponível em http://siau.edunet.sp.gov.br/ItemLise/arquivos/19 10.HTM?Time=1/8/2013\%204:38:07\%20AM. Acesso em 21/02/2012.

SÃO PAULO. Secretaria da Educação. , Resolução SE 01, de 20 de janeiro de 2011. Dispõe sobre o exercício das atribuições de Professor Mediador Escolar e Comunitário do Sistema de Proteção Escolar e dá providências correlatas. Disponível em http://edusp.blog.br/atual/2011/01/28/resolucao-se-1-de-20-1-2011/. Acesso em 25/10/2011.

SÃO PAULO. Secretaria da Educação, Resolução SE 18, de 28 de março de 2011. Altera a Resolução SE no 1, de 20 de janeiro de 2011, que dispõe sobre o exercício das atribuições de Professor Mediador Escolar e Comunitário do Sistema de Proteção Escolar e dá outras providências. Disponível http://siau.edunet.sp.gov.br/ItemLise/arquivos/18 11.HTM?Time=12/2/2012\%204:16:48\%20PM. Acesso em 24/08/2011.

SÃO PAULO. Secretaria da Educação. Instrução Conjunta CENP/DRHU de 09 de abril de 2010. Disponível http://www.dersv.com/Instru\%C3\%A7\%C3\%A3oConjuntaProte\%C3\%A7\%C3\%A3oEscolar1004201 $\underline{0 . p d f}$. Acesso em 24/08/2010.

SÃO PAULO. Secretaria da Educação. Resolução SE 07 de 19 de janeiro de 2012. Dispõe sobre o exercício das atribuições de Professor Mediador Escolar e Comunitário do Sistema de Proteção Escolar, e dá outras providências. Disponível em http://demogimirim.edunet.sp.gov.br/Index/Resolu\%C3\%A7\%C3\%A30\%20SE\%207\%20de\%2019 0 1 2012.txt. Acesso em 20/03/2012.

SÂO PAULO. Secretaria de Educação. Fundação para o Desenvolvimento da Educação. Sistema de Proteção Escolar. Manual de Proteção escolar e promoção da Cidadania. São Paulo, 2009. 83p. Disponível em http://file.fde.sp.gov.br/portalfde/Arquivo/protecao escolar web.pdf, acessado em 12/01/2013.

SOUSA, M.G. M; SILVA, V.F. Mediação de conflitos na escola. Universidade Católica de Brasília. Curso de Pedagogia. Disciplina Temas especiais em Educação e Sociedade. Taquaritinga-DF, agosto de 2006. Disponível em www.ucb.br/sites/100/127/documentos/artigo8.doc, acessado em 08/01/2012.

YIN, R.K. Estudo de caso: planejamento e métodos. Trad Ana Thorell 4a ed. Porto Alegre : Bookman, 2010. 